\title{
IMPLEMENTASI PENGELOLAAN SARANA DAN KOMUNIKASI ORGANISASI SERTA KONTRIBUSINYA TERHADAP MUTU PELAYANAN PENDIDIKAN
}

\author{
Yulianti $^{1}$, Ipong Dekawati ${ }^{2}$ \\ ${ }^{1,2}$ Universitas Wiralodra, Jln.Ir.H. Juanda Km 3 Indramayu Jawa Barat Indonesia, \\ yulianti_pasca@unwir.ac.id,ipongdekawati@unwir.ac.id
}

Received April 27, 2018, reviewed Juni 30, 2018, published September 30, 2018

Citation: Yulianti \& Dekawati, I. (2018). Implementasi Pengelolaan Sarana dan Komunikasi Organisasi Serta Kontribusinya terhadap Pelayanan Pendidikan. Edum Journal, Vol 1, No 2, Hal 69-75 September 2018.

DOI: https://doi.org/10.31943/edumjournal.v1i2.476

\begin{abstract}
ABSTRAK
Tujuannya penelitian ini yakni untuk menganalisis kontribusi implementasi pengelolaan sarana dan komunikasi organisasi baik secara parsial maupun simultan terhadap mutu pelayanan pendidikan. Metode yang digunakan adalah metode survey-deskriptif dengan pendekatan kuantitatif. Teknik pengumpulan data menggunakan angket yang sudah melalui uji validitas dan reliabilitas. Hasil penelitian menunjukkan bahwa: Baik secara parsial maupun simultan implementasi pengelolaan sarana dan komunikasi organisasi memberikan kontribusi positif terhadap mutu pelayanan pendidikan. Bertolak dari hasil penelitian tersebut, penulis menyarankan: (1) Dalam rangka meningkatkan pelayanan terhadap peserta didik, agar kelengkapan sarana yang ada dioptimalkan kuantitas dan pemeliharaannya; (2) Pihak sekolah sebaiknya mengakomodir keluhan, saran, dan aspirasi masyarakat, agar pelayanan pada masyarakat makin meningkat, terutama yang berkaitan dengan peningkatan mutu pendidikan; (3) Selalu menjalin silaturahmi dan komunikasi dengan orang tua peserta didik dalam upaya secara bersama mendorong peningkatan mutu pelayanan pendidikan.
\end{abstract}

Kata Kunci: Pengelolaaan Sarana, Komunikasi Organisasi, Mutu Pelayanan Pendidikan

\begin{abstract}
The aim of this study is to analyze the contribution of the implementation of management of organizational facilities and communication both partially and simultaneously to the quality of educational services. The method used is descriptive survey method with a quantitative approach. The data collection technique uses questionnaires that have gone through validity and reliability tests. The results of the study indicate that: Both partially and simultaneously the implementation of management of organizational facilities and communications contribute positively to the quality of education services. Starting from the results of these studies, the authors suggest: (1) In order to improve service to students, so that the completeness of existing facilities is optimized in quantity and maintenance; (2) The school should accommodate complaints, suggestions, and aspirations of the community, so that service to the community increases, especially those related to improving the quality of education; (3) Always establish friendship and communication with parents of students in an effort to jointly encourage the improvement of the quality of education services.
\end{abstract}

Keywords: Facility Management, Organizational Communication, Quality of Educational Services

PENDAHULUAN

Pendidikan merupakan jembatan untuk peningkatan kualitas sumber daya manusia yang harus secara optimal dan berkesinambungan (Nurhaidah \& Musa,

2015). Proses tersebut membutuhkan

kerjasama semua elemen masyarakat untuk memberikan pelayanan pendidikan secara 
maksimal. Pelayanan pendidikan akan memberikan kualitas di dalam pengelolaan pendidikan (Viraiyan, T.J., \& Keshwar, 2016) dan mengubah tingkah laku manusia demi menjaga kesinambungan dan peningkatan kualitas hidupnya (Kusdinar, 2014). Namun jika kita melihat konteks Indonesia, pelayanan pendidikan di Indonesia masih belum maksimal. Pemberian pelayanan pendidikan pasca reformasi masih jalan di tempat (Raihani, 2007). Padahal, pemberian pelayanan pendidikan yang bermutu akan menentukan tinggi atau rendahnya perolehan hasil belajar siswa (Kusdinar, 2014).

Oleh karena itu, pelayanan pendidikan yang bermutu adalah pemberian layanan jasa pendidikan di sekolah yang dapat memberikan kepuasan kepada para siswa di sekolah dan masyarakat atau orang tua siswa(Fadhil, 2017). Turunnya kualitas pelayanan cenderung membawa dampak buruk bagi citra sebuah sekolah, karena masyarakat yang menerima pelayanan paling tidak akan menyampaikan buruknya pelayanan tersebut kepada pihak lain dan hal ini akan membentuk opini (pendapat) umum tentang sekolah tersebut (Lipnevich \& Smith, 2008). Oleh karena itu, untuk menjaga agar sekolah memiliki citra yang baik dalam pandangan masyarakat, maka perlu dilakukan perbaikan kualitas pelayanan.
Sekolah sebagai organisasi sosial yang berkewajiban memberikan layanan bagi publik/masyarakat secara maksimal (Lipnevich \& Smith, 2008). Sekolah memiliki wewenang mengatur aspek manusia, biaya, sarana dan prasarana, dan lain-lain, yang secara langsung maupun tidak langsung (Lipnevich \& Smith, 2008). Salah satu masalah terkait dengan organisasi sekolah yakni pengelolaan sarana dan prasarana. Pengelolaan sarana pendidikan dimaksudkan untuk menunjang kegiatan sekolah agar mencapai hasil yang optimal. Sarana dan prasarana pendidikan merupakan perangkat peralatan, bahan, dan perabot yang secara langsung digunakan dalam proses pendidikan di sekolah agar tercapai tujuan pendidikan secara keseluruhan (Environment, 2013).

Sekolah harus mampu menunjukkan mutu pelayanan dalam pencapaian tujuan pendidikan secara keseluruhan (Fadhil, 2017). Dalam hal ini, mutu pelayanan berhubungan erat dengan pemenuhan sasaran individu dan akan memberikan kontribusi kepada sasaran organisasi, karena itu menjadi tugas penting bagi pihak penyelenggara dan pengelola sekolah untuk merumuskan serta menerapkan mekanisme kinerja yang tepat serta terselenggaranya manajemen yang efektif, termasuk dalam hal komunikasi organisasi (Kemendikbud, 2016). 
Kontribusi komunikasi organisasi terhadap pengembangan potensi sumber daya manusia dalam suatu sekolah sebagaimana dikemukakan di atas, memegang peranan yang sangat penting, baik komunikasi secara vertikal maupun horizontal, komunikasi verbal maupun nonverbal (Robbins \& Coulter, 2010). Bahwa salah satu kekuatan yang paling menghambat suksesnya kinerja kelompok adalah kurang efektifnya komunikasi. Komunikasi organisasi yang dibangun personil di sekolah (kepala sekolah, guru, dan tenaga kependidikan lainnya) yang memiliki kompetensi komunikasi dan profesionalisme akan memperlihatkan kemampuan dan keahliannya, sikap dan disiplin, minat dan semangat untuk bekerja dalam upaya meningkatkan kualitas pelayanan(Robbins \& Coulter, 2010).

Belum optimalnya mutu pelayanan pendidikan di sekolah dasar, ditinjau dari aspek komunikasi organisasi, berdampak pada tujuan pendidikan yang dirumuskan sekolah(Winarsih, 2017). Komunikasi organisasi yang dibangun dan diimplementasikan oleh personil sekolah dalam upaya pemberian kepuasan layanan belum optimal(Zarvedi, Yusuf, \& Ibrahim, 2016). Kepuasan dalam berkomunikasi pada suatu organisasi cenderung mempengaruhi bentuk pelayanan yang diberikan(Riyadi, Utomo, \& Masatip,
2017). Dengan demikian dapat dikatakan bahwa untuk menilai mutu pelayanan yang diberikan oleh suatu lembaga pendidikan bisa dilihat dari dua dimensi yaitu manajemen sarana dan komunikasi organisasi yang telah dibangun, dikembangkan dan diimplementasikan oleh sekolah.

Berdasarkan penjelasaan tersebut, maka peneliti tertarik untuk mengetahui sejauh mana kontribusi pengelolaan sarana dan prasarana yang maksimal dan komunikasi oragnisasi yang dilakukan oleh pimpinan terhadap mutu pelayanan sekolah yang ada di Gugus I Kecamatan Cilimus Kabupaten Kuningan.

\section{METODE PENELITIAN}

Penelitian ini dilaksanakan pada Sekolah Dasar Negeri di Gugus I Kecamatan Cilimus Kabupaten Kuningan, yang terdiri dari 36 sekolah. Populasi yang ditetapkan meliputi kepala sekolah dan guru yang berjumlah 72 orang. Karena jumlah populasinya relatif sedikit, maka semua populasi menjadi responden atau sampel jenuh. Metode yang digunakan dalam penelitian ini adalah metode surveydeskriptif dengan pendekatan kuantitatif. Pengumpulan data menggunakan teknik: studi literatur, dokumentasi dan kuesioner. Data kemudian diolah dan dianalisis menggunakan teknik analisis deskriptif dan 
verifikatif. Adapun teknik analisis sedangkan sisanya 83,1\% dipengaruhi oleh verifikatif yang digunakan adalah analisis faktor lain yang tidak diteliti

korelasi, koefisien determinasi, analisis regresi dan uji signifikansi.

\section{Analisis Pengujian Komunikasi}

\section{HASIL PENELITIAN DAN Organisasi terhadap Mutu Pelayanan}

PEMBAHASAN

\section{Pendidikan}

Analisis Pengujian Pengelolaan Sarana

Berdasarkan hasil uji t diperoleh bahwa

Prasarana terhadap Mutu Pelayanan nilai $t_{\text {hitung }}$ variabel komunikasi organisasi

\section{Pendidikan}

Untuk mengetahui besaran kontribusi pengelolaan sarana prasarana $\left(\mathrm{X}_{1}\right)$ secara individual (parsial) terhadap mutu pelayanan pendidikan. Berdasarkan hasil perhitungan uji $\mathrm{t}$ diperoleh bahwa nilai $t_{\text {hitung }}$ variabel pengelolaan sarana prasarana $\left(\mathrm{X}_{1}\right)$ memiliki nilai sebesar $p$-value $0,001<$ 0,05 artinya berdistribusi signifikan. Hal tersebut berarti pengelolaan sarana prasarana $\left(\mathrm{X}_{1}\right)$ secara parsial berkontribusi terhadap mutu pelayanan pendidikan (Y). Hasil uji anova atau $F_{\text {test }}$ sebesar 6,277 dan p-value $0,001<0,05$ sehingga $H_{0}$ ditolak artinya kontribusi pengelolaan sarana prasarana terhadap mutu pelayanan pendidikan adalah signifikan. Hasil perhitungan juga bahwa pengelolaan sarana prasarana berkontribusi sebanyak 16,9\% terhadap mutu pelayanan pendidikan,
$\left(\mathrm{X}_{2}\right)$ memiliki nilai sebesar p-value $0,000<0,05$ artinya signifikan. Dengan demikian, komunikasi organisasi $\left(\mathrm{X}_{2}\right)$ secara parsial berkontribusi terhadap mutu pelayanan pendidikan (Y). Hasil perhitungan uji anova atau $\mathrm{F}$ test diperoleh sebesar 77,013 dan p-value 0,000<0,05 sehingga $\mathrm{H}_{\mathrm{o}}$ ditolak artinya komunikasi organisasi berkontribusi signifikan terhadap mutu pelayanan pendidikan. Dari hasil perhitungan juga terlihat bahwa $\mathrm{R}^{2}$ sebesar 0,267, hal ini berarti bahwa komunikasi organisasi berkontribusi sebesar $26.7 \%$ terhadap mutu pelayanan pendidikan, sedangkan sisanya $73.3 \%$ dipengaruhi oleh faktor lain yang tidak diteliti.

Analisis Pengujian Pengelolaan Sarana

Prasarana dan Komunikasi Organisasi Terhadap Mutu Pelayanan Pendidikan 
Tabel 1 Signifikansi Kontribusi $X_{1}$ dan $X_{2}$ terhadap $Y$

Coefficients $^{\mathrm{a}}$

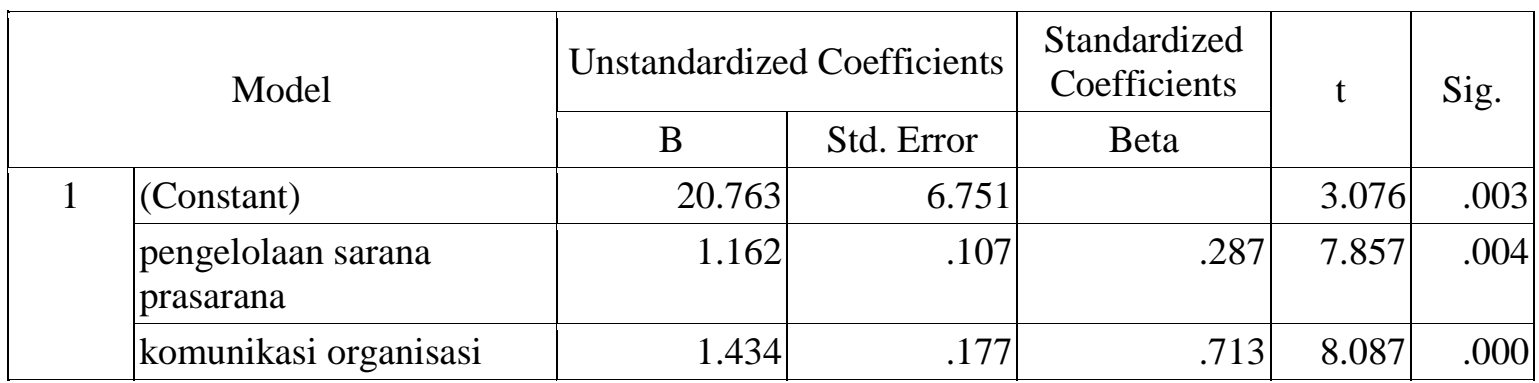

a. Dependent Variable: mutu pelayanan pendidikan

Untuk mengetahui persamaan regresi dapat dilihat dari tabel di atas. Berdasarkan tabel tersebut menunjukkan persamaan regresi linier ganda: $\hat{Y}=20,763+1,162 X 1+$ 1,434X2 Persamaan tersebut menyatakan bahwa setiap penambahan $X_{1}$ dan $X_{2}$ sebesar 1 maka akan meningkatkan Y sebesar 1,162 dan 1,434, artinya setiap peningkatan pengelolaan sarana prasarana dan komunikasi organisasi sebesar 1, akan meningkatkan mutu pelayanan pendidikan sebesar 1,162 dan 1,434. Sedangkan untuk menguji signifikansi (diukur dari tingkat signifikansi), terlihat signifikansi variabel pengelolaan sarana prasarana $\left(\mathrm{X}_{1}\right)$ sebesar 0,004 yang berarti signifikan.

Pengujian secara bersama-sama (simultan) diperoleh hasil bahwa variabel pengelolaan sarana prasarana $\left(\mathrm{X}_{1}\right)$ dan komunikasi organisasi $\left(\mathrm{X}_{2}\right)$ dapat memprediksi mutu pelayanan pendidikan (Y) secara bersama-sama. Hasil uji anova atau $F$ test didapat $F_{\text {hitung }}$ sebesar 38,728 dengan tingkat signifikansi 0,000 . Hal itu berarti variabel pengelolaan sarana prasarana $\left(\mathrm{X}_{1}\right)$ dan komunikasi organisasi $\left(\mathrm{X}_{2}\right)$ secara simultan berkontribusi terhadap mutu pelayanan pendidikan (Y). Hasil uji $\mathrm{F}$ tersebut memiliki nilai $p$-value $0,000<0,05$ artinya signifikan. Dengan demikian pengelolaan sarana prasarana $\left(\mathrm{X}_{1}\right)$ dan komunikasi organisasi $\left(\mathrm{X}_{2}\right)$ secara simultan berkontribusi terhadap mutu pelayanan pendidikan (Y). Adapun besaran kontribusi pengelolaan sarana prasarana dan komunikasi organisasi secara simultan terhadap mutu pelayanan pendidikan adalah sebesar $27,0 \%$.

\section{Pembahasan}

Secara konseptual manajemen mutu dapat diterapkan baik pada barang maupun jasa, karena yang ditekankan dalam penerapan manajemen mutu adalah perbaikan sistem kualitas, bukan sekedar perbaikan kualitas barang dan/atau jasa. Sallis (2002) menyatakan bahwa ada beberapa dimensi yang harus diperhatikan untuk meningkatkan mutu layanan, yaitu: (1) ketepatan waktu pelayanan; (2) akurasi pelayanan; (3) kesopanan dan keramahan 
dalam memberikan pelayanan; (4) tanggung jawab, berkaitan dengan penerimaan pesanan dan penanganan keluhan dari pelanggan; (5) kelengkapan; (6) kemudahan mendapatkan pelayanan; (7) variasi model pelayanan, berkaitan dengan inovasi untuk memberikan pola-pola baru dalam pelayanan; (8) pelayanan pribadi, berkaitan dengan fleksibilitas, penanganan permintaan khusus, dan lain-lain; (9) kenyamanan dalam memperoleh pelayanan; (10) atribut pendukung pelayanan lainnya, seperti: lingkungan, kebersihan, ruang tunggu, fasilitas musik, AC, dan lain-lain.

Melalui konteks mutu layananan pendidikan yang dilaksanakan oleh sekolah, maka pengguna jasa akan merasa puas.. Bertolak dari hasil penelitian di atas memberi gambaran bahwa oleh karena pengelolaan sarana prasarana dan komunikasi organisasi berkontribusi baik secara parsial maupun ganda terhadap mutu pelayanan pendidilan, maka salah satu cara untuk meningkatkan mutu pelayanan pendidikan adalah dengan melengkapi sarana dan sarana pendidikan secara tepat dan proporsional serta mengoptimalkan komunikasi organisasi di sekolah.

\section{KESIMPULAN}

Berdasarkan hasil analisis dan pembahasan yang telah dikemukakan sebelumnya, maka dapat disampaikan kesimpulan sebagai berikut:

Pengelolaan sarana prasarana memiliki kontribusi signifikan terhadap mutu pelayanan pendidikan. (2) Komunikasi organisasi memiliki kontribusi signifikan terhadap mutu pelayanan pendidikan. (3) Pengelolaan sarana prasarana dan komunikasi organisasi secara simultan memiliki kontribusi signifikan terhadap mutu pelayanan pendidikan.

\section{UCAPAN TERIMAKASIH}

Terimkasih kepada semua pihak yang telah membantu penulisan karya ilmiah ini.

\section{DAFTAR PUSTAKA}

Environment, C. on P. A. and P. E. in the S. (2013). Educating the Student Body: Taking Physical Activity and Physical Education to School (Harold W.). The National Academies Press. Retrieved from nap.edu

Fadhil, M. (2017). Manajemen Peningkatan Mutu Pendidikan. TADBIR: Jurnal Studi Manajemen Pendidikan, 1(02), 205-239.

Kemendikbud. (2016). Rencana Strategis Kementerian Pendidikan dan Kebudayaan 2015-2019 (2016).

Kusdinar, M. (2014). Pengaruh Kemampuan Profesional Guru dan Motivasi Guru BK Terhadap Layanan Bimbingan (Studi pada Guru BK SMA di Kabupaten Ciamis). Jurnal Ilmiah Mahasiswa Pascasarjana Admistrasi Pendidikan, 2(1), 65-67. https://doi.org/10.16309/j.cnki.issn.10 07-1776.2003.03.004 
Lipnevich, A. A., \& Smith, J. K. (2008). Response To Assessment Feedback: the Effects of Grades, Praise, and Source of Information. ETS Research Report Series (Vol. 2008). https://doi.org/10.1002/j.2333-

8504.2008.tb02116.x

Nurhaidah, \& Musa, M. I. (2015). Pelayanan Pendidikan yang Berkualitas di Era Global dan Mengembangkan Potensi Peserta Didika secara Maksimal. Jurnal Pesona Dasar, 1(4), 52-65.

Raihani. (2007). Education reforms in Indonesia in the twenty-first century. International Education Journal, 8(1), 172-183.

Riyadi, H., Utomo, B. S., \& Masatip, A. (2017). Pengaruh Komunikasi , Motivasi Kerja Dan Kompetensi Terhadap Kepuasan Kerja Serta Implikasinya Pada Kinerja Dosen Pada Perguruan Tinggi Pariwisata Swasta Di Jawa Barat, 7(2), 73-90.

Robbins, S. P., \& Coulter, M. (2010). Management. Prentice-Hall, Inc.A Pearson Education Company, Upper Saddle River, New Jersey

Sallis, E. (2002). Total Quality Management in Education. Kogan Page Ltd 120 Pentonville Road London N1 9JN UK \& Stylus Publishing Inc 22883 Quicksilver Drive Sterling VA 20166-2012 USA.

Viraiyan, T., T.J., K., \& Keshwar, S. (2016). an Analysis of Higher Education Service Quality in Mauritius Using Hesqual. International Journal of Business Research, 16(2), 89-104. https://doi.org/10.18374/IJBR-16-2.7

Winarsih, S. (2017). Kebijakan dan implementasi manajemen pendidikan tinggi dalam meningkatkan mutu pendidikan. Cendekia, 15(1), 51-66.

Zarvedi, R., Yusuf, R., \& Ibrahim, M. (2016). Pengaruh kepemimpinan, budaya organisasi dan kompetensi terhadap kinerja pegawai serta implikasinya pada kinerja sekretariat kabupaten pidie jaya. Jurnal Perspektif Ekonomi Darusalam, 2(2), 201-217. 